\title{
Influence of Tumour Necrosis Factor Alpha on the Outcome of Ischaemic Postconditioning in the Presence of Obesity and Diabetes
}

\author{
Lydia Lacerda, Lionel H. Opie, and Sandrine Lecour \\ Cardioprotection Group, Hatter Institute for Cardiovascular Research in Africa, Department of Medicine, Faculty of Health Sciences, \\ University of Cape Town, Anzio Road, Observatory, Cape Town 7925, South Africa \\ Correspondence should be addressed to Lydia Lacerda, lacerdal@sun.ac.za
}

Received 26 June 2012; Revised 10 September 2012; Accepted 10 September 2012

Academic Editor: N. Cameron

Copyright ( $) 2012$ Lydia Lacerda et al. This is an open access article distributed under the Creative Commons Attribution License, which permits unrestricted use, distribution, and reproduction in any medium, provided the original work is properly cited.

Obesity and diabetes contribute to cardiovascular disease and alter cytokine profile. The cytokine, tumour necrosis factor alpha $(\mathrm{TNF} \alpha)$, activates a protective signalling cascade during ischaemic postconditioning (IPostC). However, most successful clinical studies with IPostC have not included obese and/or diabetic patients. We aimed to investigate the influence of TNF $\alpha$ on the outcome of IPostC in obese or diabetic mice. TNF knockout or wildtype mice were fed for 11 weeks with a high carbohydrate diet (HCD) to induce modest obesity. Diabetes was induced in a separate group by administration of a single intraperitoneal injection of streptozotocin. Hearts were then isolated and subjected to ischaemia ( $35 \mathrm{~min}$ of global ischaemia) followed by $45 \mathrm{~min}$ of reperfusion. HCD increased body weight, plasma insulin and leptin levels while the glucose level was unchanged. In streptozotocintreated mice, blood glucose, plasma leptin and insulin were altered. Control, obese or diabetic mice were protected with IPostC in wiltype animals. In TNF knockout mice, IPostC failed to protect control and diabetic hearts while a slight protection was observed in obese hearts. Our data confirm a bidirectional role for TNF $\alpha$ associated with the severity of concomitant comorbidities and suggest that diabetic and/or modestly obese patients may still benefit from IPostC.

\section{Introduction}

Both obesity and diabetes are major risk factors for cardiovascular disease. Forty years ago, fewer than 25\% of adults in the USA were classified as overweight or obese compared with $75 \%$ in 2002 [1-3]. Because the onset of typel diabetes occurs at a young age, the cardiovascular risk is increased tenfold when compared with nondiabetic peers [4]. In addition, obesity and diabetes are associated with an increased mortality and an attenuation of tolerance to ischaemic events $[5,6]$.

Experimental data suggest that the protective effect of ischaemic postconditioning (IPostC) (defined as a series of brief episodes of alternating reperfusion and ischaemia at the onset of reperfusion) is diminished in animals with comorbidities such as obesity and diabetes; see review [7]. Bouhidel demonstrated that the protective effect of IPostC against reperfusion injury in ob/ob mice was impaired [8].
Furthermore, obesity and diabetes compromise the inflammatory system with altered expression of tumour necrosis factor alpha (TNF $\alpha)$ occurring in adipose and muscle tissue of obese humans [9]. However, whether this alteration is beneficial or deleterious to the heart still remains unclear. The expression of adipokines, such as leptin, is also modified in obesity and diabetes and there is a strong correlation between serum leptin and TNF $\alpha$ levels [10]. Additionally, leptin has been reported to protect against lethal reperfusion injury in the isolated mouse heart via direct action on the heart $[11,12]$.

A dual role for TNF $\alpha$ in the heart has been postulated whereby beneficial effects are seen at low concentrations and deleterious effects become evident at higher concentrations in a time-dependent manner [13-15]. TNF $\alpha$ can activate both TNF receptor 1 and TNF receptor 2 which seem to exert opposite effects in the heart [16]. In a mouse model, we have recently shown that a low concentration of $\mathrm{TNF} \alpha$ activates 


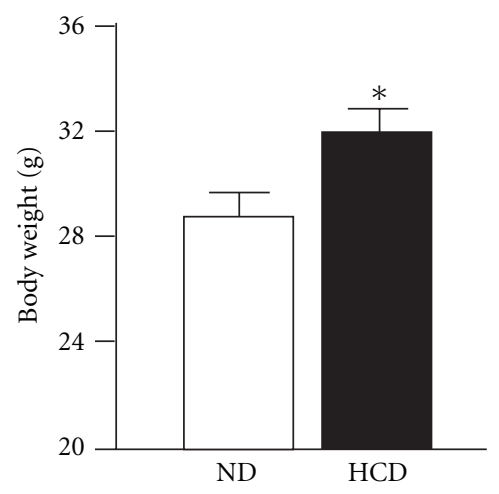

(a)

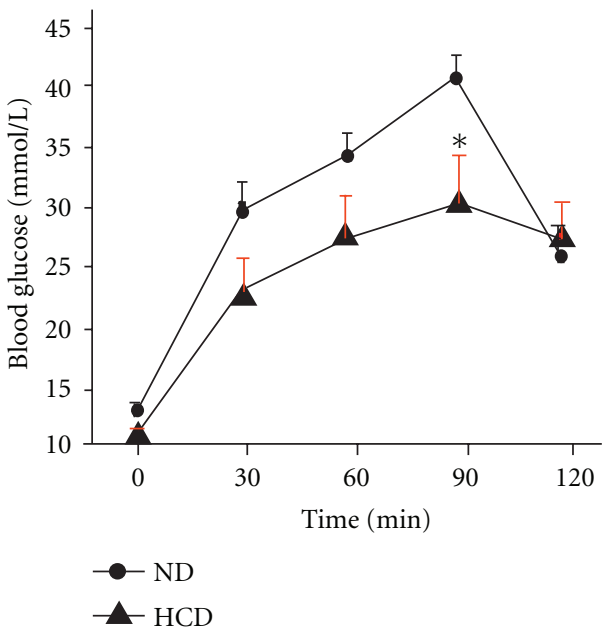

(d)

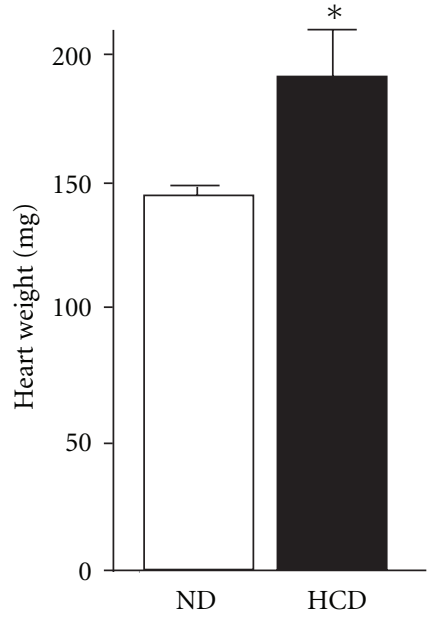

(b)

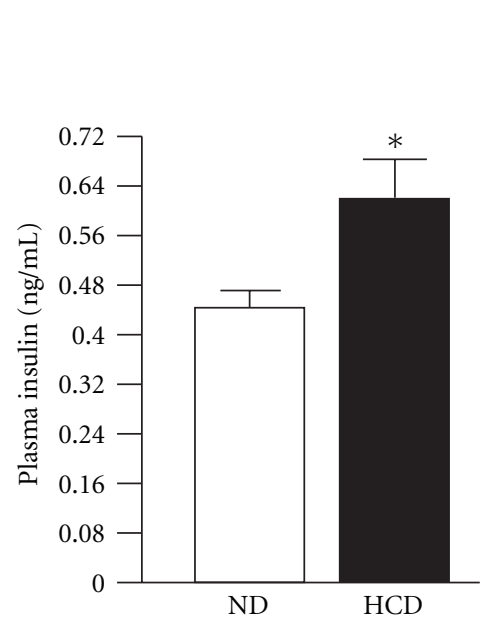

(e)

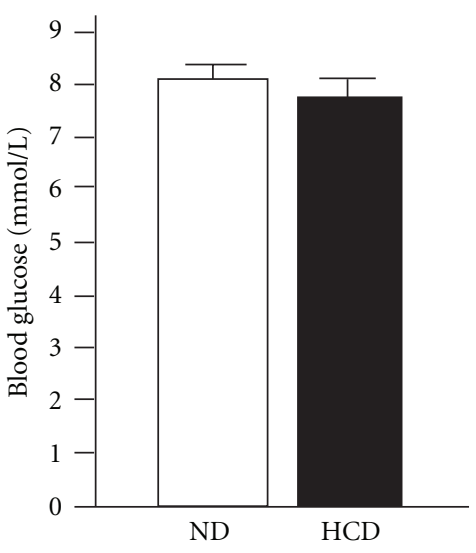

(c)

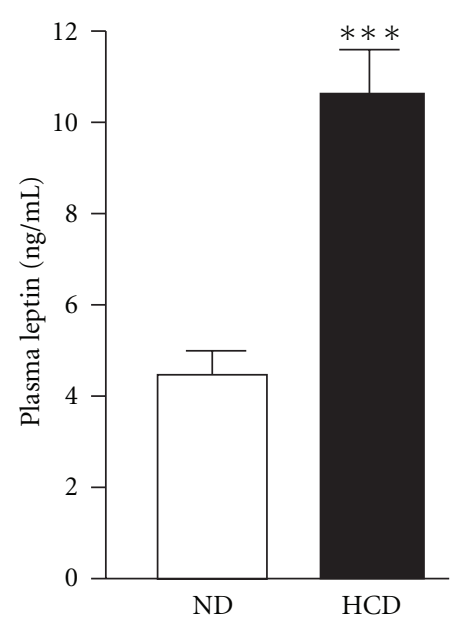

(f)

FIGURE 1: Effects of high carbohydrate diet (HCD) on physiological parameters in TNF-WT mice. HCD increased body weight (a), heart weight (b), plasma insulin (e) and plasma leptin levels (f), decreased blood glucose tolerance test (d) but no significant difference was observed on blood glucose levels (c), ${ }^{*} P<0.05 ;{ }^{* *} P<0.001$ versus normal diet (ND); $n \geq 6$ for all groups.

TABLE 1: Energy provided by high carbohydrate diet (HCD) versus normal chow (ND).

\begin{tabular}{lcc}
\hline & $\begin{array}{c}\text { Normal diet } \\
(\mathrm{ND})\end{array}$ & $\begin{array}{c}\text { High-carbohydrate diet } \\
(\mathrm{HCD})\end{array}$ \\
\hline Carbohydrates (\%) & 60 & 69 \\
Proteins (\%) & 30 & 17 \\
Fats (\%) & 10 & 14 \\
\hline
\end{tabular}

a protective signalling cascade during IPostC via the activation of the TNF receptor 2 [17]. However, the outcome of IPostC in obese and diabetic patients remains uncertain as the recent application of this therapy in clinical studies has excluded patients with such comorbidities.

In the present study, we aimed to investigate the influence of TNF $\alpha$ on the outcome of IPostC in obese or diabetic mice.

\section{Methods}

All animal studies performed were approved by the Animal Research Ethics Committee of the University of Cape Town and followed the recommendations laid down in the Guide for the Care and Use of Laboratory Animals published by the US National Institute of Health (NIH Publication no. 85-23, revised 1996).

2.1. High-Carbohydrate Diet (HCD) Mouse Model. Wildtype (TNF-WT) and TNF $\alpha$ knockout $\left(\mathrm{TNF}^{-}{ }^{-}\right)$mice were separated into 2 groups each, with 6 mice per group. One group of TNF-WT and one group of $\mathrm{TNF}^{-}{ }^{-}$mice each received a normal diet (ND) of mouse chow and the second groups of TNF-WT and $\mathrm{TNF}^{-} /^{-}$each received a diet containing elevated carbohydrates and fats mimicking a Western-type diet (HCD), for 11 weeks as illustrated in Table 1 [5]. 


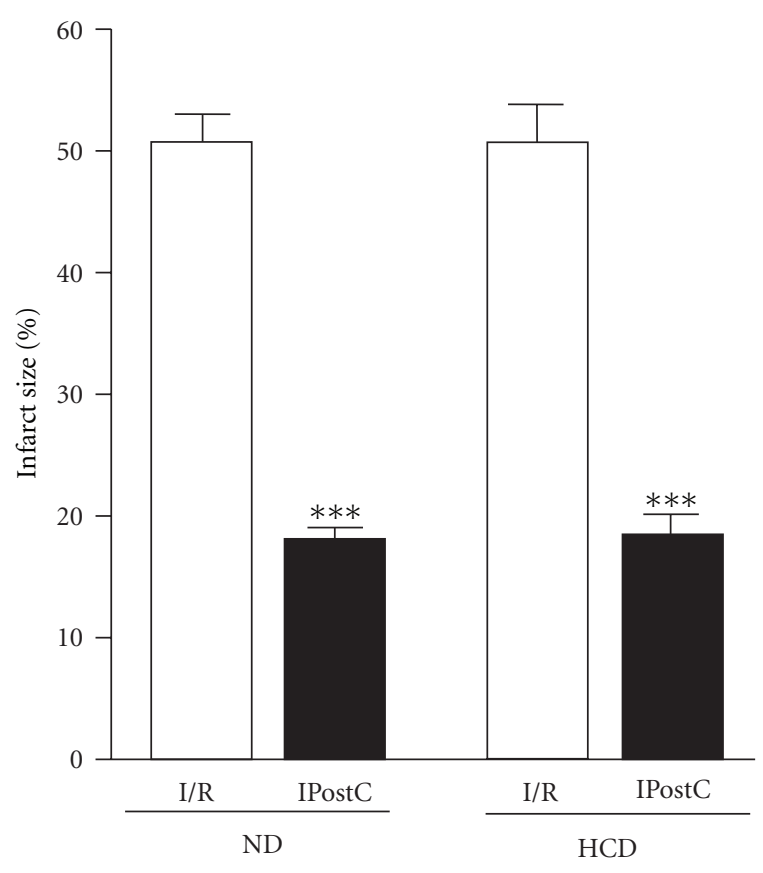

FIgURE 2: Effect of obesity on IPostC-induced cardioprotection in isolated TNF-WT hearts. IPostC in TNF-WT with normal diet (ND) reduced infarct size from $50 \pm 2 \%$ in the ischaemic control group (I/R) to $18 \pm 1 \%$ for IPostC. The infarct size in TNF-WT with high carbohydrate diet (HCD) was decreased to $19 \pm 2 \%$ versus $50 \pm 2 \%$ for the I/R group, ${ }^{* * *} P<0.001$ versus I/R; $n \geq 6$.

2.2. Streptozotocin Diabetic Mouse Model (STZ). Experimental diabetes type 1 was induced in a total of 10 mice per group by a single intraperitoneal (i.p.) injection of $180 \mathrm{mg}$ streptozotocin (STZ)/kg body weight, dissolved in $0.1 \mathrm{~mol}$ citrate buffer [18]. Nondiabetic control animals were treated with solvent (citrate buffer) alone. Standard mouse chow and tap water were provided ad libitum for all groups. At the end of each time period, only STZ-treated mice with a blood glucose level greater than $16 \mathrm{mmol} / \mathrm{L}$ were considered as diabetic (normal blood glucose levels in mice range from 3.4 to $9.7 \mathrm{mmol} / \mathrm{L}$ ). Of the $10 \mathrm{STZ}$-treated TNF-WT mice, 7 met the criteria, 2 did not achieve sufficiently high glucose levels, and 1 died shortly after receiving the STZ. No death occurred in the 10 Nondiabetic control animals in each group.

2.3. Blood Glucose and Glucose Tolerance Test. Blood glucose and the glucose tolerance test (GTT) were done at 14 weeks. Mice were fed normal chow or HCD as described in Table 1. Prior to performing the blood glucose tolerance test, the mice were fasted for 7 hours, but had free access to drinking water. A $20 \%$ solution (w/v) of glucose was made up in sterile distilled water. Each mouse was then sedated with a mixture of ketamine $(75 \mathrm{mg} / \mathrm{kg})$ and medetomidine $(0.5 \mathrm{mg} / \mathrm{kg})$ given i.p. Body weight was recorded for each mouse; a tail cut was done and blood glucose determined in $\mathrm{mmol} / \mathrm{L}$ by means of a blood glucose monitor (Accu-Chek Active; Roche Diagnostics, Mannheim, Germany) as per the manufacturer's instructions. A bolus of glucose was given i.p.
(15 mg/kg). Thereafter, a blood glucose measurement was performed every $30 \mathrm{~min}$ after injection, until a decrease in the glucose level was observed (120 to $150 \mathrm{~min}$ ).

2.4. Perfusion of Mouse Hearts. The HCD-fed mice (14 weeks of age), the STZ-treated mice (5 and 10 days after STZ treatment), and their respective controls were anaesthetized (sodium pentobarbitone, $60 \mathrm{mg} / \mathrm{kg}$ i.p.) and heparinized (25 IU i.p.). Hearts were isolated and perfused retrogradely as previously described [19]. At the same time, blood was taken from the thoracic cavity of each mouse and placed in a chilled heparinized tube, centrifuged at $5000 \mathrm{rpm}$ for $5 \mathrm{~min}$ at 4 degrees. The plasma was removed and frozen for further analysis.

2.5. Ischaemic Postconditioning. HCD-fed mice and STZtreated mice were subjected to the ischaemic postconditioning (IPostC) protocol which consisted of six alternating cycles of 10-second reperfusion, 10-second ischaemia, commencing at the onset of reperfusion as described previously [17].

2.6. Ratio of Heart Weight to Body Weight. At the end of the perfusion protocol, each heart was carefully dried and weighed after staining with triphenyl tetrazolium chloride (TTC). The heart weight to body weight ratio for each mouse was then calculated.

2.7. Insulin Levels. Quantitative determination of baseline insulin levels was performed using the Ultrasensitive Mouse Insulin Elisa Kit (Crystal Chem Inc.; USA) as per the manufacturer's instructions.

2.8. Leptin Levels. Quantitative determination of baseline leptin levels was performed using the Ultrasensitive Mouse Leptin Elisa Kit (Crystal Chem Inc; USA) as per the manufacturer's instructions.

2.9. Chemicals and Pharmacological Agents. Unless otherwise stated, all chemicals were obtained from Sigma-Aldrich Chemicals, Germany.

2.10. Statistical Analysis. Data are presented as mean \pm SEM. Comparisons between multiple groups were performed by 1-way ANOVA followed by Tukey post hoc test or Bonferroni multiple comparison test (GraphPad Instat). Twoway ANOVA followed by Bonferroni multiple comparison test (GraphPad Prism) was performed where species or diet differed. $P<0.05$ was considered to be statistically significant.

\section{Results}

3.1. Effect of High Carbohydrate Diet on Physiological Parameters in TNF-WT Mice. HCD increased the body and heart weights in the TNF-WT mice from $29.0 \pm 1.0$ grams to $32.0 \pm 0.7$ grams $(P<0.05$ versus ND; Figures $1(\mathrm{a})$ and $1(\mathrm{~b}))$. Although HCD did not affect baseline blood glucose levels 


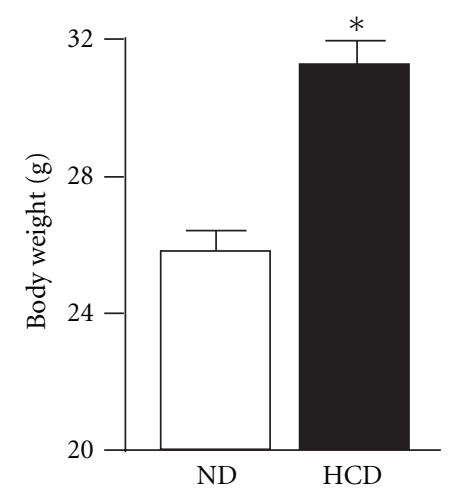

(a)

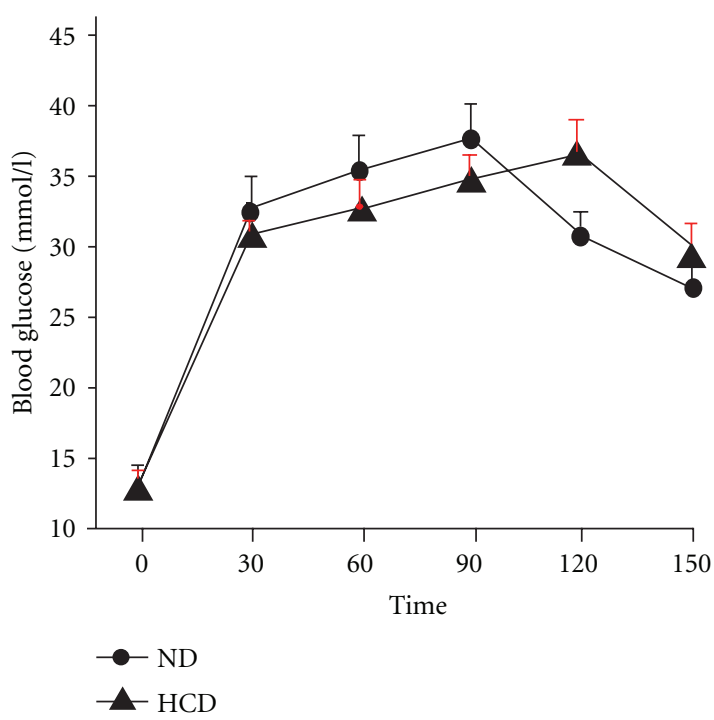

(d)

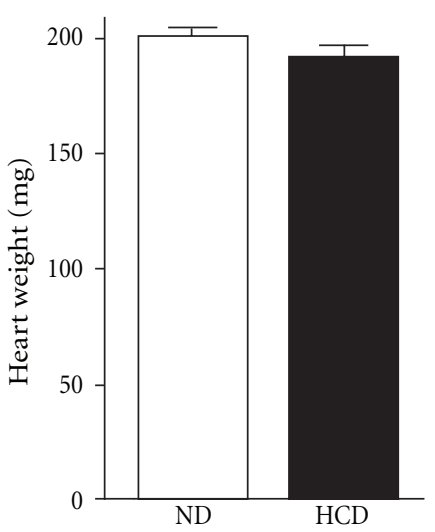

(b)

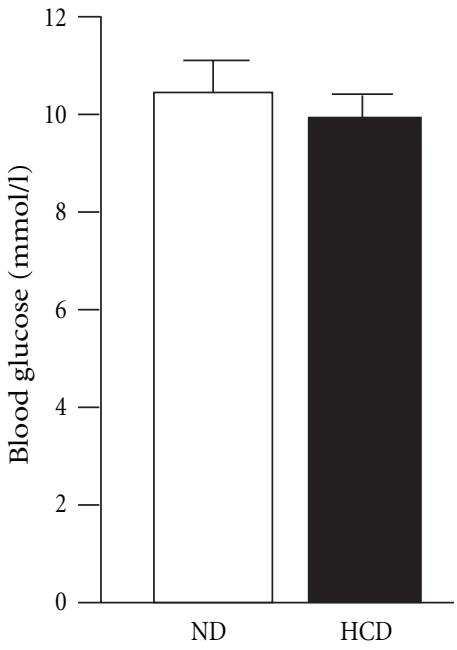

(c)

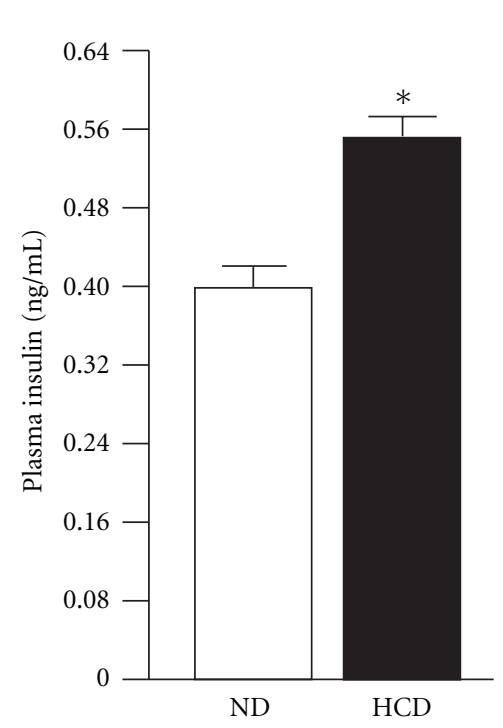

(e)

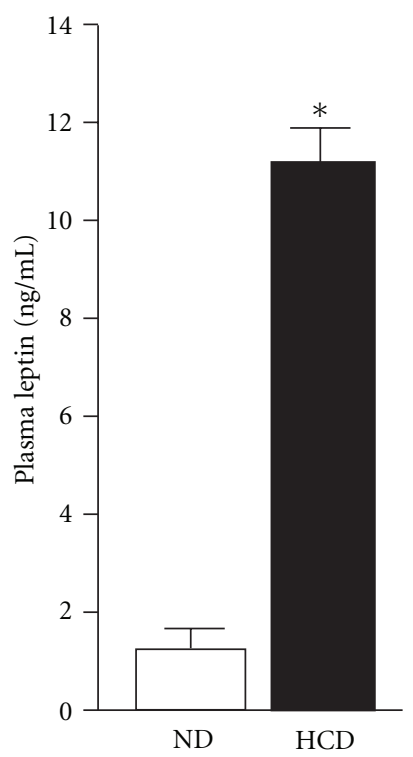

(f)

FiguRe 3: Effects of obesity on physiological parameters in $T N^{-/-}$mice. High carbohydrate diet (HCD) increased body weight (a), plasma insulin (e) and plasma leptin levels, whereas blood glucose levels (c) and heart weight (b) remained unchanged. ${ }^{*} P<0.05$ versus normal $\operatorname{diet}(\mathrm{ND}) ; n=6$ for all groups.

$(P=$ ns, Figure $1(\mathrm{c}))$ it improved glucose tolerance in the WT animals $(P<0.05$ versus ND, Figure $1(\mathrm{~d}))$ and increased plasma insulin and leptin levels to $0.64 \pm 0.06 \mathrm{ng} / \mathrm{mL}$ from $0.46 \pm 0.03 \mathrm{ng} / \mathrm{mL}$ in ND $(P<0.05)$ and to $10.6 \pm 0.9 \mathrm{ng} / \mathrm{mL}$ from $4.5 \pm 0.4 \mathrm{ng} / \mathrm{mL}$ in ND $(P<0.001$, resp., Figures $1(\mathrm{e})$ and $1(\mathrm{f}))$.

3.2. Effect of High Carbohydrate Diet on IPostC-Induced Cardioprotection in TNF-WT Hearts. Mice on the ND presented a similar infarct size to those fed an HCD mice when subjected to $\mathrm{I} / \mathrm{R}(P=\mathrm{ns})$. IPostC reduced the infarct size to a similar extent in ND and HCD mice versus their respective ischaemia-reperfusion control groups $(P<0.001)$ (Figure 2).
3.3. Effect of High Carbohydrate Diet on Physiological Parameters in $\mathrm{TNF}^{-} /^{-}$Mice. $\mathrm{TNF}^{-} /^{-}$mice were used to investigate the role of TNF $\alpha$ in obesity. Similar to TNF-WT mice, body weight was increased with HCD from $26.0 \pm 0.4$ grams to $31.5 \pm 0.5$ grams $(P<0.05$ versus ND, Figure $3(\mathrm{a}))$. However, there was no change in heart weight in $\mathrm{TNF}^{-} /^{-}$mice on the HCD compared to their ND counterparts $(P=\mathrm{ns}$, Figure 3(b)).

Baseline blood glucose and tolerance of HCD-fed TNFdeficient mice to glucose remained unchanged by HCD, $(P=$ ns; Figures 3(c) and 3(d)). Plasma insulin levels were increased significantly by HCD from $0.41 \pm 0.02 \mathrm{ng} / \mathrm{mL}$ to $0.57 \pm 0.01 \mathrm{ng} / \mathrm{mL}(P<0.05$ versus ND, Figure $3(\mathrm{e}))$. Similarly, the plasma leptin levels were significantly increased 


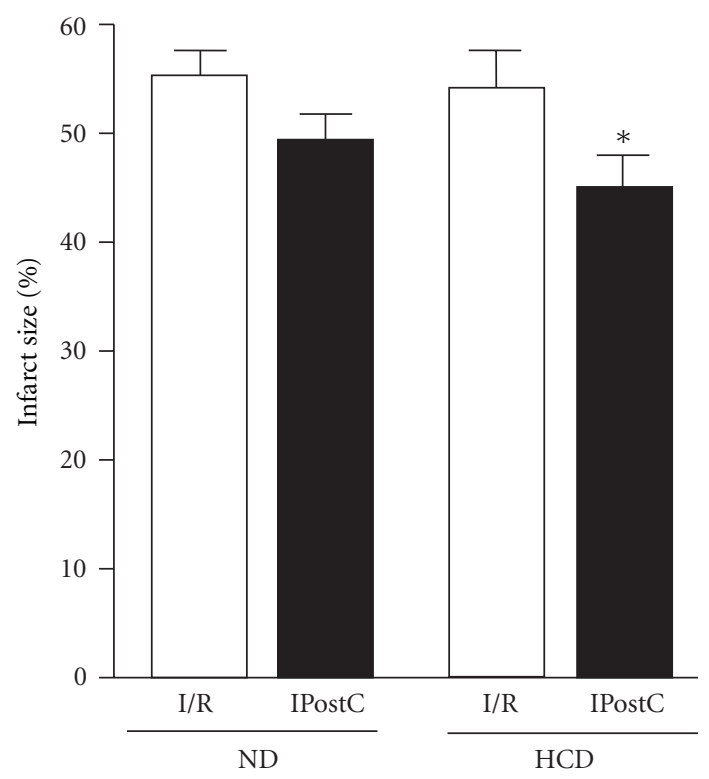

FIGURE 4: Effect of obesity on IPostC-induced cardioprotection in isolated $\mathrm{TNF}^{-/-}$mice. IPostC reduced infarct size in the HCD fed mice from $56 \pm 2 \%$ to $45 \pm 4 \%$ whereas mice fed the normal diet could not be protected, ${ }^{*} P<0.05$ versus I/R; $n \geq 6$.

by the HCD from $1.3 \pm 0.08 \mathrm{ng} / \mathrm{mL}$ to $11.2 \pm 0.8 \mathrm{ng} / \mathrm{mL}$ $(P<0.05$ versus ND, Figure $3(f))$.

\subsection{Effect of High Carbohydrate Diet on IPostC-Induced Car-} dioprotection of $\mathrm{TNF}^{-} /^{-}$Hearts. To determine whether absence of TNF $\alpha$ in obesity can affect the outcome of IPostC, the isolated hearts of $\mathrm{TNF}^{-} /^{-}$mice fed with either a normal diet or an HCD were subjected to the IPostC protocol. HCD mice subjected to $\mathrm{I} / \mathrm{R}$ presented a similar infarct size compared to mice fed with ND $(P=$ ns). Surprisingly, the hearts from $\mathrm{TNF}^{-} /^{-}$mice fed with $\mathrm{HCD}$ demonstrated a slight reduction in infarct size versus the I/R control $(P<$ 0.05; Figure 4).

3.5. Effects of Diabetes on Physiological Parameters in TNFWT Mice. To create a type 1 diabetic model, TNF-WT mice were given a single intraperitoneal injection of streptozotocin $(180 \mathrm{mg} / \mathrm{kg}$ body weight). Physiological parameters and experiments were performed either 5 days or 10 days after STZ administration. TNF-WT mice had a significant decrease in body weight 5 days after treatment, from $29.7 \pm$ 1.3 grams to $21.0 \pm 2.6$ grams $(P<0.001$ versus no STZ). However, the weight was restored by day $10(P=$ ns versus no STZ; Figure 5(a)). There was no change in the heart weight after 5 days of STZ $(P=$ ns; Figure 5(b)), whereas, after 10 days after STZ treatment, the heart weight was significantly increased $(P<0.01$ versus untreated controls). Streptozotocin injection increased baseline blood glucose at days 5 and $10(P<0.01$ versus no STZ; Figure 5(c)), but decreased plasma insulin from $1.02 \pm 0.2 \mathrm{ng} / \mathrm{mL}$ to $0.53 \pm$ $0.14 \mathrm{ng} / \mathrm{mL}$ (5 days after STZ) and to $0.36 \pm 0.02 \mathrm{ng} / \mathrm{mL}$ (10 days after STZ) $(P<0.05$ versus no STZ-treatment; Figure 5(d)). Similar results for glucose and insulin after streptozotocin treatment have been reported [20]. Leptin levels were also reduced by STZ at day 5 and 10 after injection from $4.5 \pm 0.7 \mathrm{ng} / \mathrm{mL}$ to $0.6 \pm 0.2 \mathrm{ng} / \mathrm{mL}$ and $0.23 \pm$ $0.04 \mathrm{ng} / \mathrm{mL}$, respectively $(P<0.001$ versus no STZ treatment; Figure 5(e)).

3.6. Effect of Diabetes on IPostC-Induced Cardioprotection in TNF-WT Hearts. STZ-treated TNF-WT mice subjected to I/R showed a similar infarct size to the untreated I/R control, at both 5 days and 10 days after treatment $(P<0.001$ versus I/R). STZ treatment did not affect the cardioprotective effect of IPostC after 5 or 10 days versus the untreated animals, $(P<0.001$; Figure 6).

3.7. Effect of Diabetes on Physiological Parameters in $\mathrm{TNF}^{-} \mathrm{I}^{-}$ Mice. To investigate whether TNF $\alpha$ plays a role in type 1 diabetes and cardiovascular disease, TNF $\alpha$-deficient mice were injected intraperitoneally with a single dose of streptozotocin $(180 \mathrm{mg} / \mathrm{kg}$ body weight). Similar to TNF-WT mice, STZ administration had no effect on body weight, 5 or 10 days after STZ treatment $(P=$ ns, Figure $7(a))$. However, the heart weight was significantly decreased by the STZ treatment after 5 days $(P<0.001$ versus untreated, Figure $7(\mathrm{~b})$ ) but 10 days after treatment the heart weight was similar to untreated controls $(P=$ ns versus untreated, Figure $7(\mathrm{~b}))$. As expected, STZ increased baseline blood glucose at both time points $(P<0.001$ versus untreated, Figure $7(\mathrm{c}))$. Although no significant difference was seen in plasma insulin levels at 5 days after STZ treatment, there was a significant increase 10 days after treatment, from $0.32 \pm$ $0.1 \mathrm{ng} / \mathrm{mL}$ to $1.06 \pm 0.3 \mathrm{ng} / \mathrm{mL}(P<0.01$ versus untreated control, Figure $7(\mathrm{~d}))$. Similarly to the TNF-WT mice, the diabetic $\mathrm{TNF}^{-} /^{-}$animals demonstrated an elevated level of plasma leptin at 5 days after STZ administration, from $2.3 \pm 0.1 \mathrm{ng} / \mathrm{mL}$ to $3.0 \pm 0.4(P<0.001$ versus untreated control), but the leptin level was drastically reduced in the 10 -day post-treatment group to $0.3 \pm 0.08 \mathrm{ng} / \mathrm{mL}(P<0.05$ versus untreated control group, Figure $7(\mathrm{e}))$.

3.8. Effect of Diabetes on IPostC-Induced Cardioprotection in $\mathrm{TNF}^{-}{ }^{-}$Hearts. IPostC failed to confer protection in the STZ-treated TNF $\alpha$ knockout animals $(P=$ ns versus I/R; Figure 8).

\section{Discussion}

Our data revealed that 11 weeks of a high-carbohydrate diet, or the administration of a single intraperitoneal injection of streptozotocin, resulted in a modest model of obesity or diabetes, as demonstrated by changes in body weight, blood glucose levels, plasma insulin, and plasma leptin levels. IPostC-induced cardioprotection was evident in the modestly obese TNF-WT mice and also in the diabetic TNFWT mice, suggesting that the presence of obesity/diabetes did not alter the cardioprotective signalling cascade activated by IPostC. However, in the absence of TNF $\alpha$, the IPostC stimulus did not protect the healthy and diabetic mice against I/R injury. Surprisingly, there was slight restoration of the cardioprotective effect in the modestly obese $\mathrm{TNF}^{-} /^{-}$ 


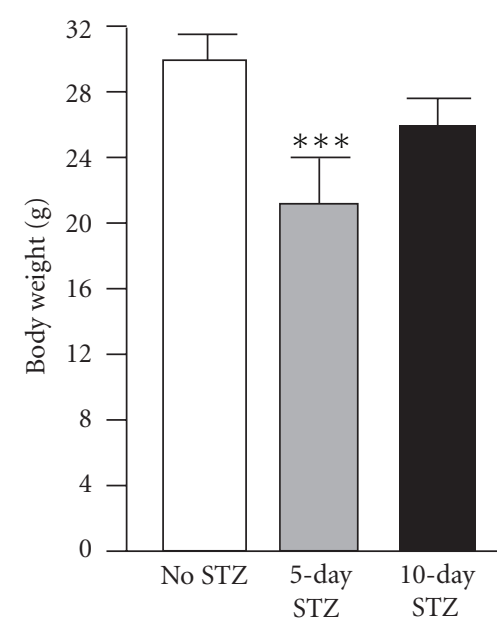

(a)

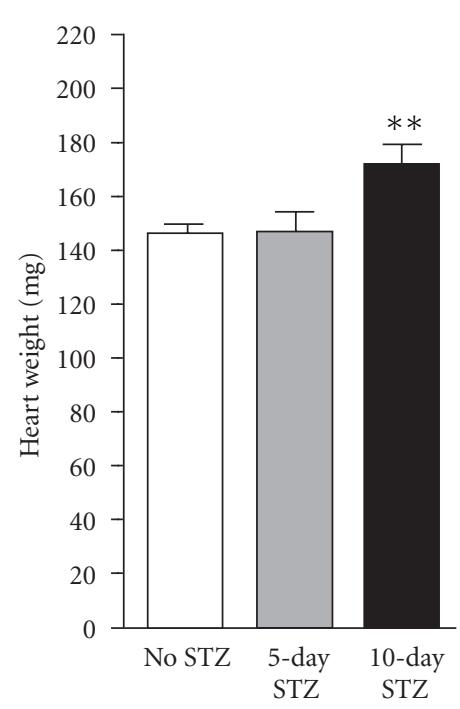

(b)

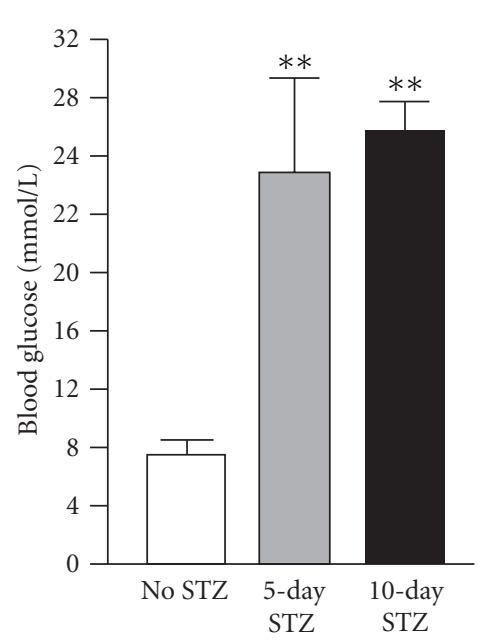

(c)

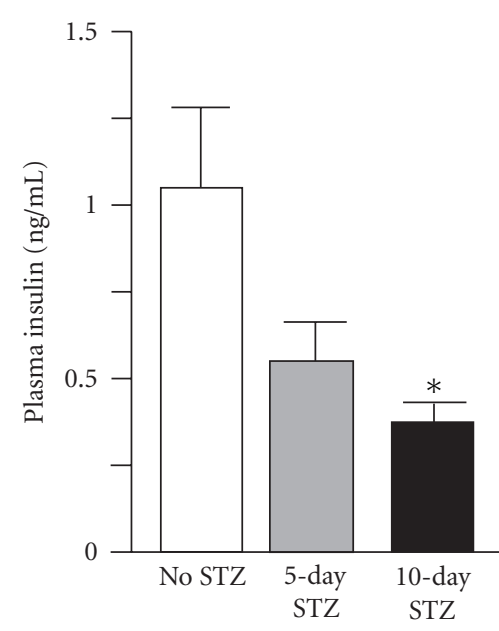

(d)

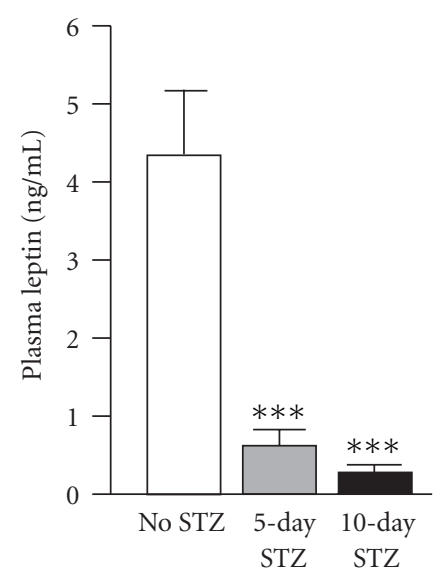

(e)

FIGURE 5: Effects of diabetes on physiological parameters in TNF-WT mice. Body weight was decreased 5 days post STZ treatment and returned to normal at day 10 post STZ treatment (a). Heart weight was reduced 10 days post STZ treatment (b). Insulin and leptin levels were both decreased with post STZ treatment ( $\mathrm{d}$ and e) while STZ increased baseline blood glucose at days 5 and $10,{ }^{*} P<0.05$ and ${ }^{* * *} P<0.001$ versus no STZ.

animals, reinforcing the concept that $\mathrm{TNF} \alpha$ has both deleterious and beneficial effects in the heart.

\subsection{Obesity/Diabetes and Susceptibility to Ischaemia-Reper-} fusion. Many of the signalling cascades involved in cardioprotection may be affected by various factors such as preexisting disease, age, and cotreatments [21, 22]. To date, cardioprotective investigations have been performed mainly in young and healthy animals, which is far different from the clinical setting $[23,24]$. The high-carbohydrate diet used in our study is of a similar composition than the conventional Western-type diet of humans and was chosen to represent a modestly obese phenotype [5], unlike the more severe obese models of either ob/ob mice or the $\mathrm{db} / \mathrm{db}$ mice which are either leptin deficient or have no leptin receptors. In our model, high-carbohydrate diet did not affect the damage following ischemia-reperfusion. Obesity is associated with hyperinsulinaemia which markedly modulates the extent to which myocardial injury occurs during ischaemiareperfusion [25]. Therefore, it is plausible to suggest that, in obesity, the impact of high levels of circulating insulin during ischaemia and reperfusion could overshadow myocardial susceptibility to ischaemia-reperfusion injury.

4.2. Obesity/Diabetes Susceptibility to IPC and IPostC. Our data demonstrate that obesity, induced by a highcarbohydrate diet or diabetes, induced by injection of streptozotocin, did not affect the cardioprotective effect of IPostC in the wildtype animals. Failure of IPostC to limit infarct size was reported from a study conducted in $\mathrm{ob} / \mathrm{ob}$ mice [8]. However, a limitation of this study was the lack of leptin in this mouse strain. A very recent study 


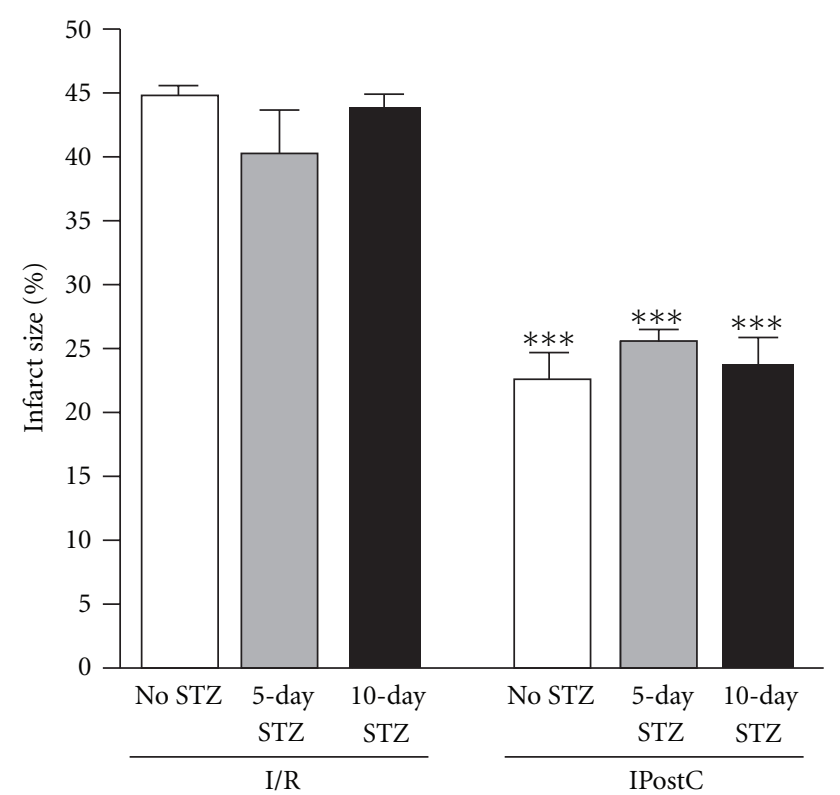

Figure 6: Effect of diabetes on IPostC induced cardioprotecion in isolated TNF-WT mice. Infarct size was significantly decreased by IPostC in control and streptozotocin treated animals, ${ }^{* * *} P<0.001$ versus respective $\mathrm{I} / \mathrm{R}$ controls.

conducted in a murine model of streptozotocin-induced diabetes (using a similar dose to our study) reported a loss of efficacy in IPostC-induced cardioprotection [26]. Possible explanations for the contradiction between this study and our present findings are as follows: (1) the insulin levels in the mice of the published study were significantly lower $(0.18 \pm 0.08 \mathrm{ng} / \mathrm{mL})$ than the insulin levels found in our diabetic mice $(0.36 \pm 0.02 \mathrm{ng} / \mathrm{mL})$; (2) the difference in mouse species, (3) the difference in age of the animals, and (4) the number of $I / R$ cycles performed to postcondition the heart. The ischemic postconditioning algorithm chosen may influence the postconditioning effect [27]. In our study, we have used 6 cycles while published studies that failed to postcondition the diabetic heart have used 3 cycles [26]. It is possible that the threshold of protection has been raised with 6 cycles. We have recently reported that age, strain, and the postconditioning algorithm are critical factors to consider for successful cardioprotection with postconditioning and a minute difference in age, for example, can lead to an opposite outcome [28].

4.3. TNF $\alpha$ and Myocardial Function. Although TNF $\alpha$ is known to have a detrimental effect in ischaemia-reperfusion [29], we have previously demonstrated that TNF $\alpha$ is required for the protection with ischaemic pre- and postconditioning $[17,30]$. In fact, $\mathrm{TNF} \alpha$ is cardioprotective in a dose- and time- dependent manner [31]. Depending on which TNF receptor is activated, TNF $\alpha$ can be either harmful or protective with the activation of the TNF receptor 1 being harmful and the activation of the receptor 2 being protective [17, 32]. The cardioprotective effect of TNF $\alpha$ initiates a prosurvival signalling cascade termed as the survivor activating factor enhancement (SAFE) pathway that involves the activation of the transcription factor STAT-3 and possibly the closure of the mitochondrial permeability transition pore $[33,34]$.

4.4. Role of TNF $\alpha$ in Obese and Diabetic Animals. The role of TNF $\alpha$ in diet-induced obesity may depend on the TNF receptors activated with TNF receptor 1 being deleterious and TNF receptor 2 being cardioprotective [35]. Our data showed that the body weight was increased by $21 \%$ in $\mathrm{TNF}^{-} /^{-}$mice fed with HCD versus only $11 \%$ in the TNFWT mice subjected to the same regime, therefore suggesting a protective effect of TNF $\alpha$ in diet-induced obesity. It would be of interest to repeat our experiments in our $\mathrm{TNF}^{-} /^{-}$, TNFR $1^{-} l^{-}$, and TNFR2 $2^{-} l^{-}$animals to further delineate the role of TNF $\alpha$ receptors in our model.

The presence of TNF $\alpha$ in obesity has been reported to contribute towards the development of cardiac hypertrophy in cardiomyocytes [35]. In support of this hypothesis, our data demonstrate an increase in the heart weight in the TNFWT mice fed with an HCD whereas, in the absence of TNF $\alpha$, the HCD had no effect on the heart weight.

In our obese and diabetic models, the absence of TNF $\alpha$ did not affect the damage in hearts subjected to ischemiareperfusion. However, it is important to note that our ischemia-reperfusion insult was performed in vitro and it may not translate to an in vivo setting.

$\mathrm{TNF} \alpha$ production is markedly increased in muscle and adipose tissue in obese humans and rodent models of obesity-diabetes, compared with tissues of lean individuals [36]. The risk of cardiac microvascular disease is also increased in the diabetic individual and the release of circulating microparticles may favour the release of TNF $\alpha$ from endothelial cells [37]. Several studies have demonstrated that $\mathrm{TNF} \alpha$ plays a role in mediating insulin resistance as a result of obesity [38-40]. Three factors which contribute to the control of body weight have been linked to TNF $\alpha$ : (1) the intake of food, (2) expenditure of energy, and (3) storage of energy.

Administration of TNF $\alpha$ in a rat model resulted in reduced food intake [41] and also inhibited gastric emptying, leading to a feeling of satiation, most likely due to activation of leptin $[42,43]$. Neutralization of TNF $\alpha$ by intravenous administration of a soluble TNF receptor-immunoglobulin $\mathrm{G}$ chimeric protein provided a significant improvement in insulin sensitivity in fatty rats [38-40], but treatment of noninsulin-dependent diabetes mellitus patients with a specific TNF $\alpha$ antibody had no effect on insulin sensitivity [44].

Although TNF $\alpha$ has been proposed as a link between obesity and insulin resistance [45], the baseline blood glucose was unchanged by HCD in the TNF-WT and $\mathrm{TNF}^{-} \rho^{-}$mice in our study. However, plasma insulin levels were increased, therefore suggesting the development of insulin resistance, even in the absence of TNF $\alpha$.

Surprisingly, the high carbohydrate diet slightly restored the protective effect of IPostC in the TNF-deficient mice, therefore suggesting that absence of TNF $\alpha$ in obesity may be of benefit to the heart. In our modestly obese $\mathrm{TNF}^{-} l^{-}$mice, the plasma leptin level was significantly elevated compared to the animals kept on the normal diet where IPostC-induced 


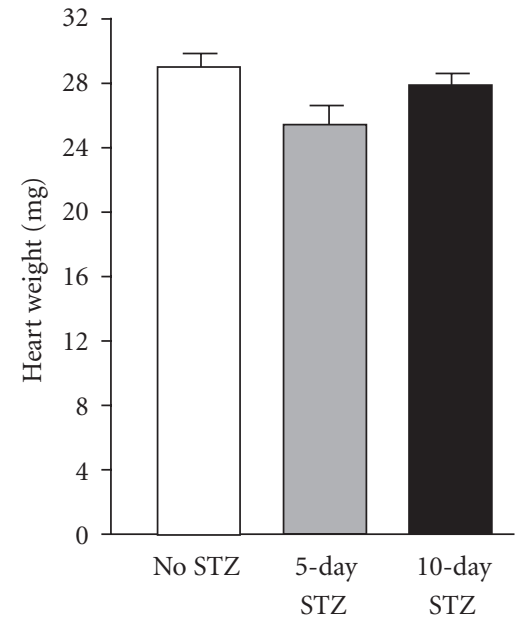

(a)

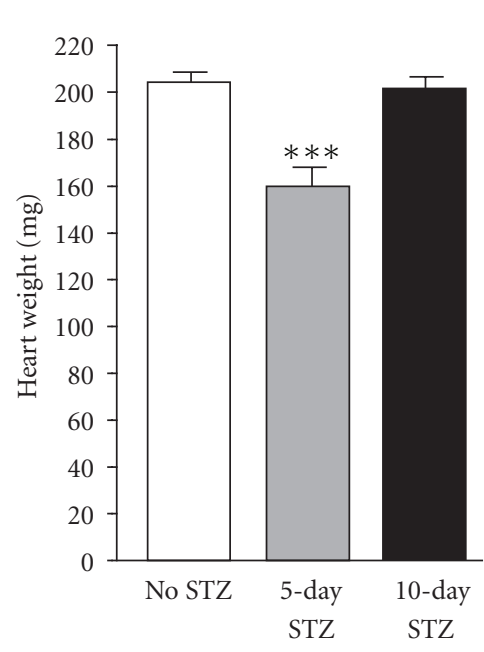

(b)

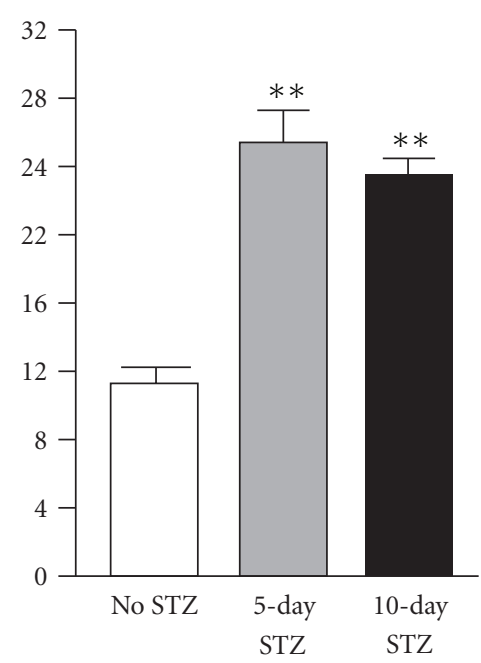

(c)

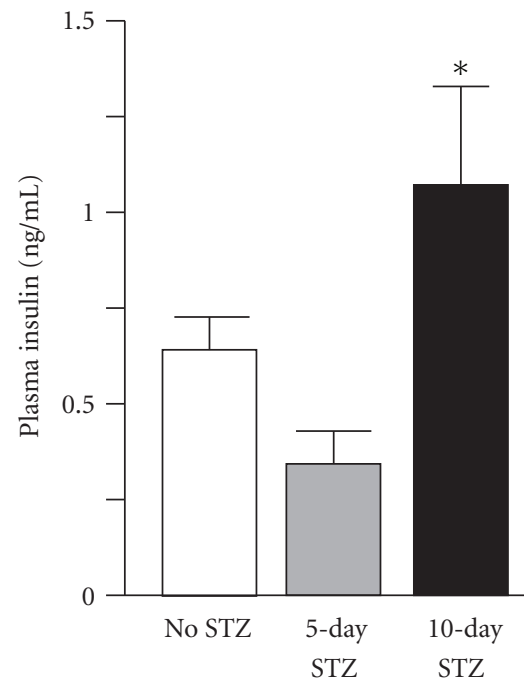

(d)

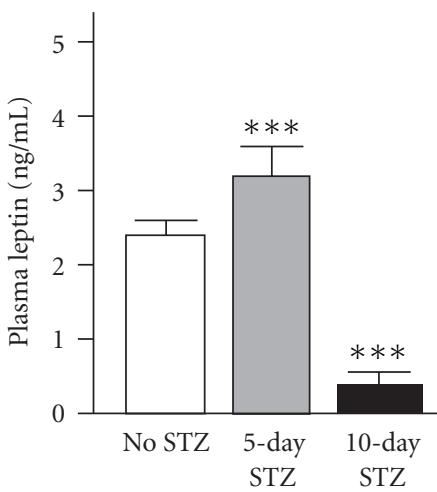

(e)

FIGURE 7: Effects of diabetes on physiological parameters in $\mathrm{TNF}^{-/-}$mice. Body weight remained unchanged in Streptozotocin (STZ)-treated mice (a) but decreased the heart weight 5 days post treatment (b). mice (a) but decreased the heart weight 5 days post treatment (b). Blood glucose (c), plasma insulin (d) and plasma leptin (e) were increased with STZ, ${ }^{*} P<0.05,{ }^{* *} P<0.01,{ }^{* * *} P<0.001$ versus no STZ; $n=6$.

protection was abrogated, therefore suggesting that this adipokine may be implicated in a compensatory mechanism. Leptin has been demonstrated to exhibit direct cardioprotective effects by targeting the mitochondrial permeability transition pore [11]. It is possible that the increased level of leptin in obesity might in fact protect the individuals with a higher body mass index after a myocardial infarction $[22,46,47]$.

The increased plasma leptin levels observed in our $\mathrm{TNF}^{-} /^{-}$mice correlate with an increase in body weight and the same correlation was found in mice fed with a high-fat diet [48]. In contrast to our obese $\mathrm{TNF}^{-} /^{-}$mice, our STZinduced diabetic TNF-WT model had significantly decreased leptin levels and the protective effect of IPostC was not significant. It has recently been reported that the tissuepreserving actions of leptin are influenced by obesity [48].
Dixon's group showed that leptin decreased the infarct size in Wistar and Zucker lean rats, which have functional leptin receptors, but the cardioprotection was lost in the Zucker obese rats in which the leptin receptors are nonfunctional [49]. These data provided evidence suggesting that the tissuepreserving actions of leptin are influenced by the severe obesity seen in Zucker obese rats. Thus, the degree of obesity as well as the presence or absence of TNF $\alpha$ may be of importance in determining the protective effects of leptin.

\section{Conclusion}

In conclusion, our data demonstrate that the cardioprotective effect of IPostC was unaltered in a high-carbohydrate diet mouse model of obesity and streptozotocin-induced diabetes. Whilst TNF $\alpha$ is necessary for the maintenance of 


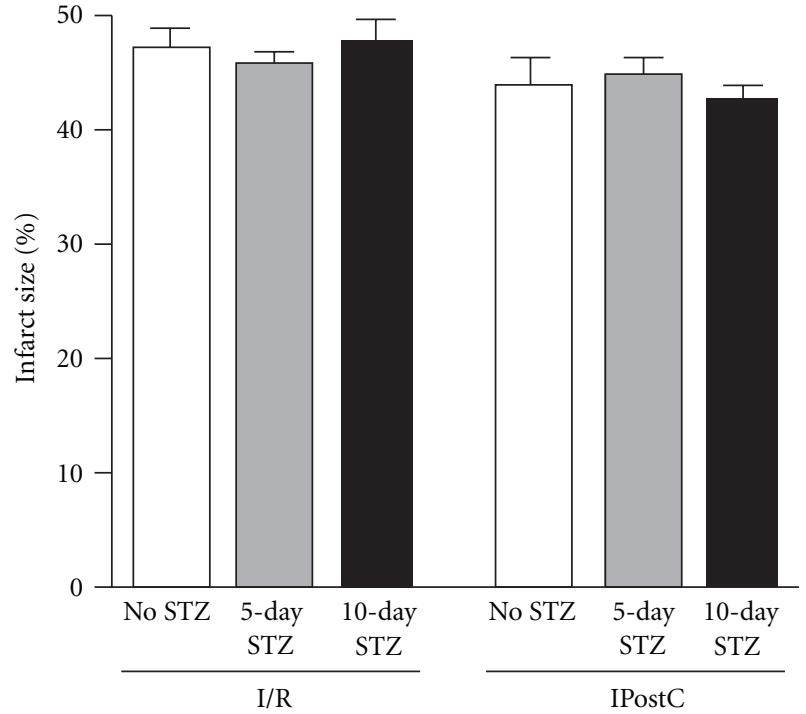

Figure 8: Effect of diabetes on IPostC induced cardioprotecion in isolated $\mathrm{TNF}^{-/-}$mice. Ischaemic postconditioning failed to protect hearts from $\mathrm{TNF}^{-/-}$mice both at 5 and 10 days after STZ-treatment, $P=\mathrm{ns} ; n=6$.

glucose homeostasis, for the control of appetite to prevent obesity and for IPostC-induced cardioprotection, it can also lead to cardiac hypertrophy. The absence of TNF in mice did not affect the outcome of obese and diabetic mice subjected to an ischemia-reperfusion insult. IpostC failed to protect in healthy or obese $\mathrm{TNF}^{-} /^{-}$mice. However, a slight protection with IPostC was observed in our $\mathrm{TNF}^{-} /^{-}$model in the presence of obesity, illustrating the bidirectional effect of TNF $\alpha$ in the heart and the fact that the role of TNF $\alpha$ in obesity- and diabetes-related ischaemic heart disease remains a complex system. Nevertheless, our data suggest that obese and type 1 diabetic individuals may still benefit from IPostC, relative to the severity of the disease.

\section{Conflict of Interests}

The authors declare that there is no duality of interests associated with this paper.

\section{Acknowledgments}

This study was supported by the Medical Research Council, South Africa, the National Research Foundation in South Africa, and the University of Cape Town.

\section{References}

[1] K. M. Flegal, M. D. Carroll, C. L. Ogden, and C. L. Johnson, "Prevalence and trends in obesity among US adults, 19992000," JAMA, vol. 288, no. 14, pp. 1723-1727, 2002.

[2] C. J. Lavie and R. V. Milani, "Obesity and cardiovascular disease: the Hippocrates paradox?" Journal of the American College of Cardiology, vol. 42, no. 4, pp. 677-679, 2003.

[3] J. E. Manson and S. S. Bassuk, "Obesity in the United States: a fresh look at its high toll," JAMA, vol. 289, no. 2, pp. 229-230, 2003.
[4] T. J. Orchard, T. Costacou, A. Kretowski, and R. W. Nesto, "Type 1 diabetes and coronary artery disease," Diabetes Care, vol. 29, no. 11, pp. 2528-2538, 2006.

[5] E. Aasum, A. M. Khalid, O. A. Gudbrandsen, O. J. How, R. K. Berge, and T. S. Larsen, "Fenofibrate modulates cardiac and hepatic metabolism and increases ischemic tolerance in diet-induced obese mice," Journal of Molecular and Cellular Cardiology, vol. 44, no. 1, pp. 201-209, 2008.

[6] D. Aronson, L. A. Weinrauch, J. A. D'Elia, G. H. Tofler, and A. J. Burger, "Circadian patterns of heart rate variability, fibrinolytic activity, and hemostatic factors in type I diabetes mellitus with cardiac autonomic neuropathy," American Journal of Cardiology, vol. 84, no. 4, pp. 449-453, 1999.

[7] M. N. Sack and E. Murphy, "The role of comorbidities in cardioprotection," Journal of Cardiovascular Pharmacology and Therapeutics, vol. 16, no. 3-4, pp. 267-272, 2011.

[8] O. Bouhidel, S. Pons, R. Souktani, R. Zini, A. Berdeaux, and B. Ghaleh, "Myocardial ischemic postconditioning against ischemia-reperfusion is impaired in ob/ob mice," American Journal of Physiology, vol. 295, no. 4, pp. H1580-H1586, 2008.

[9] G. S. Hotamisligil, P. Arner, J. F. Caro, R. L. Atkinson, and B. M. Spiegelman, "Increased adipose tissue expression of tumor necrosis factor- $\alpha$ in human obesity and insulin resistance," The Journal of Clinical Investigation, vol. 95, no. 5, pp. 2409-2415, 1995.

[10] S. Margetic, C. Gazzola, G. G. Pegg, and R. A. Hill, "Leptin: a review of its peripheral actions and interactions," International Journal of Obesity, vol. 26, no. 11, pp. 1407-1433, 2002.

[11] C. C. T. Smith, M. M. Mocanu, S. M. Davidson, A. M. Wynne, J. C. Simpkin, and D. M. Yellon, "Leptin, the obesityassociated hormone, exhibits direct cardioprotective effects," British Journal of Pharmacology, vol. 149, no. 1, pp. 5-13, 2006.

[12] C. C. T. Smith, R. A. Dixon, A. M. Wynne et al., "Leptininduced cardioprotection involves JAK/STAT signaling that may be linked to the mitochondrial permeability transition pore," American Journal of Physiology, vol. 299, no. 4, pp. H1265-H1270, 2010.

[13] A. Skyschally, P. Gres, S. Hoffmann et al., "Bidirectional role of tumor necrosis factor- $\alpha$ in coronary microembolization: progressive contractile dysfunction versus delayed protection against infarction," Circulation Research, vol. 100, no. 1, pp. 140-146, 2007.

[14] M. N. Sack, "Tumor necrosis factor- $\alpha$ in cardiovascular biology and the potential role for anti-tumor necrosis factor- $\alpha$ therapy in heart disease," Pharmacology and Therapeutics, vol. 94, no. 1-2, pp. 123-135, 2002.

[15] R. Schulz, "TNF $\alpha$ in myocardial ischemia/reperfusion: damage vs. protection," Journal of Molecular and Cellular Cardiology, vol. 45, no. 6, pp. 712-714, 2008.

[16] R. Schulz and G. Heusch, "Editorial: tumor necrosis factor$\alpha$ and its receptors 1 and 2: yin and yang in myocardial infarction?" Circulation, vol. 119, no. 10, pp. 1355-1357, 2009.

[17] L. Lacerda, S. Somers, L. H. Opie, and S. Lecour, "Ischaemic postconditioning protects against reperfusion injury via the SAFE pathway," Cardiovascular Research, vol. 84, no. 2, pp. 201-208, 2009.

[18] K. K. Wu and Y. Huan, "Streptozotocin-induced diabetic models in mice and rats," Current Protocols in Pharmacology, vol. 40, pp. 5.47.1-5.47.14, 2008.

[19] R. M. Smith, N. Suleman, J. McCarthy, and M. N. Sack, "Classic ischemic but not pharmacologic preconditioning is abrogated following genetic ablation of the TNF $\alpha$ gene," Cardiovascular Research, vol. 55, no. 3, pp. 553-560, 2002. 
[20] T. Nakamura, T. Terajima, T. Ogata et al., "Establishment and pathophysiological characterization of type 2 diabetic mouse model produced by streptozotocin and nicotinamide," Biological and Pharmaceutical Bulletin, vol. 29, no. 6, pp. 1167$1174,2006$.

[21] M. Ovize, G. F. Baxter, F. Di Lisa et al., "Postconditioning and protection from reperfusion injury: where do we stand: position Paper from the Working Group of Cellular Biology of the Heart of the European Society of Cardiology," Cardiovascular Research, vol. 87, no. 3, pp. 406-423, 2010.

[22] G. Heusch, "Obesity-a risk factor or a RISK factor for myocardial infarction?" British Journal of Pharmacology, vol. 149, no. 1, pp. 1-3, 2006.

[23] D. J. Hausenloy, G. Baxter, R. Bell et al., "Translating novel strategies for cardioprotection: the Hatter Workshop Recommendations," Basic Research in Cardiology, vol. 105, no. 6, pp. 677-686, 2010.

[24] L. Schwartz Longacre, R. A. Kloner, A. E. Arai et al., "New horizons in cardioprotection: recommendations from the 2010 national heart, lung, and blood institute workshop," Circulation, vol. 124, no. 10, pp. 1172-1179, 2011.

[25] B. N. Fuglesteg, N. Suleman, C. Tiron et al., "Signal transducer and activator of transcription 3 is involved in the cardioprotective signalling pathway activated by insulin therapy at reperfusion," Basic Research in Cardiology, vol. 103, no. 5, pp. 444-453, 2008.

[26] K. Przyklenk, M. Maynard, D. L. Greiner, and P. Whittaker, "Cardioprotection with postconditioning: loss of efficacy in murine models of type-2 and type-1 diabetes," Antioxidants and Redox Signaling, vol. 14, no. 5, pp. 781-790, 2011.

[27] A. Skyschally, P. van Caster, E. K. Iliodromitis, R. Schulz, D. T. Kremastinos, and G. Heusch, "Ischemic postconditioning: experimental models and protocol algorithms," Basic Research in Cardiology, vol. 104, no. 5, pp. 469-483, 2009.

[28] S. J. Somers, L. Lacerda, L. Opie, and S. Lecour, "Age, genetic characteristics and number of cycles are critical factors to consider for successful protection of the murine heart with postconditioning," Physiological Research, vol. 60, no. 6, pp. 971-974, 2011.

[29] P. Kleinbongard, G. Heusch, and R. Schulz, "TNF $\alpha$ in atherosclerosis, myocardial ischemia/reperfusion and heart failure," Pharmacology and Therapeutics, vol. 127, no. 3, pp. 295-314, 2010.

[30] S. Lecour, N. Suleman, G. A. Deuchar et al., "Pharmacological preconditioning with tumor necrosis factor- $\alpha$ activates signal transducer and activator of transcription-3 at reperfusion without involving classic prosurvival kinases (Akt and extracellular signal-regulated kinase)," Circulation, vol. 112, no. 25, pp. 3911-3918, 2005.

[31] S. Lecour, R. M. Smith, B. Woodward, L. H. Opie, L. Rochette, and M. N. Sack, "Identification of a novel role for sphingolipid signaling in TNF $\alpha$ and ischemic preconditioning mediated cardioprotection," Journal of Molecular and Cellular Cardiology, vol. 34, no. 5, pp. 509-518, 2002.

[32] L. Lacerda, J. McCarthy, S. F. K. Mungly et al., "TNF $\alpha$ protects cardiac mitochondria independently of its cell surface receptors," Basic Research in Cardiology, vol. 105, no. 6, pp. 751-762, 2010.

[33] S. Lecour, "Activation of the protective Survivor Activating Factor Enhancement (SAFE) pathway against reperfusion injury: does it go beyond the RISK pathway?" Journal of Molecular and Cellular Cardiology, vol. 47, no. 1, pp. 32-40, 2009.
[34] K. Boengler, D. Hilfiker-Kleiner, G. Heusch, and R. Schulz, "Inhibition of permeability transition pore opening by mitochondrial STAT3 and its role in myocardial ischemia/reperfusion," Basic Research in Cardiology, vol. 105, no. 6, pp. 771$785,2010$.

[35] T. Yokoyama, M. Nakano, J. L. Bednarczyk, B. W. McIntyre, M. Entman, and D. L. Mann, "Tumor necrosis factor- $\alpha$ provokes a hypertrophic growth response in adult cardiac myocytes," Circulation, vol. 95, no. 5, pp. 1247-1252, 1997.

[36] G. S. Hotamisligil, N. S. Shargill, and B. M. Spiegelman, "Adipose expression of tumor necrosis factor- $\alpha$ : direct role in obesity-linked insulin resistance," Science, vol. 259, no. 5091, pp. 87-91, 1993.

[37] S. Montoro-García, E. Shantsila, F. Marín, A. Blann, and G. Y. H. Lip, "Circulating microparticles: new insights into the biochemical basis of microparticle release and activity," Basic Research in Cardiology, pp. 1-13, 2011.

[38] S. A. Schreyer, S. C. Chua, and R. C. Leboeuf, "Obesity and diabetes in TNF- $\alpha$ receptor-deficient mice," The Journal of Clinical Investigation, vol. 102, no. 2, pp. 402-411, 1998.

[39] G. S. Hotamisligil, D. L. Murray, L. N. Choy, and B. M. Spiegelman, "Tumor necrosis factor $\alpha$ inhibits signaling from the insulin receptor," Proceedings of the National Academy of Sciences of the United States of America, vol. 91, no. 11, pp. 4854-4858, 1994.

[40] G. S. Hotamisligil and B. M. Spiegelman, "Tumor necrosis factor $\alpha$ : a key component of the obesity-diabetes link," Diabetes, vol. 43, no. 11, pp. 1271-1278, 1994.

[41] N. J. Rothwell, "Cytokines and thermogenesis," International Journal of Obesity, vol. 17, supplement 3, pp. S98-S115, 1993.

[42] M. J. Fargeas, J. Fioramonti, and L. Bueno, "Central action of interleukin $1 \beta$ on intestinal motility in rats: mediation by two mechanisms," Gastroenterology, vol. 104, no. 2, pp. 377-383, 1993.

[43] J. Arbos, F. J. Lopez-Soriano, N. Carbo, and J. M. Argiles, "Effects of tumour necrosis factor- $\alpha$ (cachectin) on glucose metabolism in the rat. Intestinal absorption and isolated enterocyte metabolism," Molecular and Cellular Biochemistry, vol. 112, no. 1, pp. 53-59, 1992.

[44] G. S. Hotamisligil, A. Budavari, D. Murray, and B. M. Spiegelman, "Reduced tyrosine kinase activity of the insulin receptor in obesity- diabetes. Central role of tumor necrosis factor- $\alpha$," The Journal of Clinical Investigation, vol. 94, no. 4, pp. 1543-1549, 1994.

[45] G. S. Hotamisligil, "Inflammatory pathways and insulin action," International Journal of Obesity, vol. 27, supplement 3, pp. S53-S55, 2003.

[46] L. M. A. Kennedy, K. Dickstein, S. D. Anker, K. Kristianson, and R. Willenheimer, "The prognostic importance of body mass index after complicated myocardial infarction," Journal of the American College of Cardiology, vol. 45, no. 1, pp. 156$158,2005$.

[47] E. Nikolsky, G. W. Stone, C. L. Grines et al., "Impact of body mass index on outcomes after primary angioplasty in acute myocardial infarction," American Heart Journal, vol. 151, no. 1, pp. 168-175, 2006.

[48] R. A. Dixon, S. M. Davidson, A. M. Wynne, D. M. Yellon, and C. C. T. Smith, "The cardioprotective actions of leptin are lost in the zucker obese (fa/fa) rat," Journal of Cardiovascular Pharmacology, vol. 53, no. 4, pp. 311-317, 2009.

[49] R. A. Dixon, S. M. Davidson, A. M. Wynne, D. M. Yellon, and C. C. T. Smith, "The cardioprotective actions of leptin are lost in the zucker obese (fa/fa) rat," Journal of Cardiovascular Pharmacology, vol. 53, no. 4, pp. 311-317, 2009. 


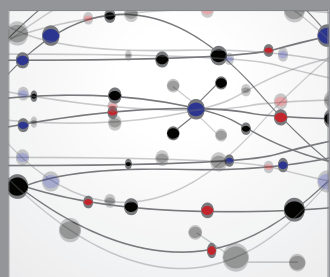

The Scientific World Journal
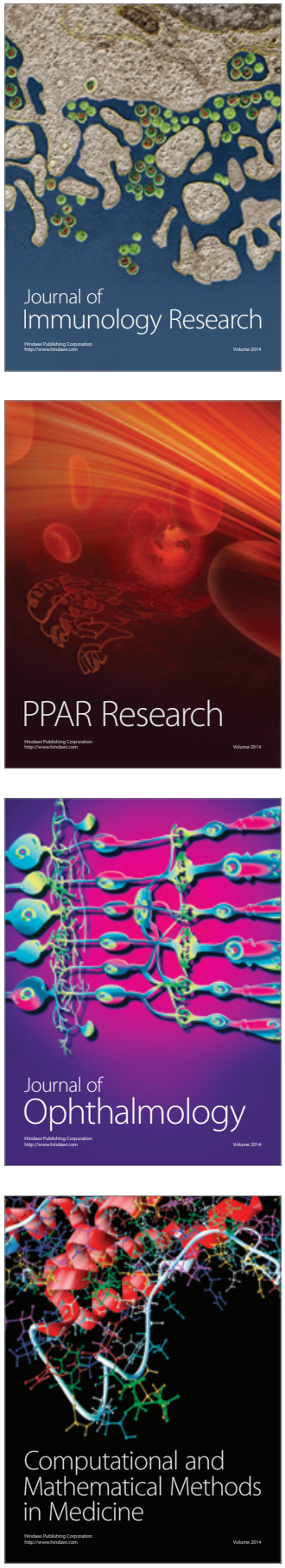

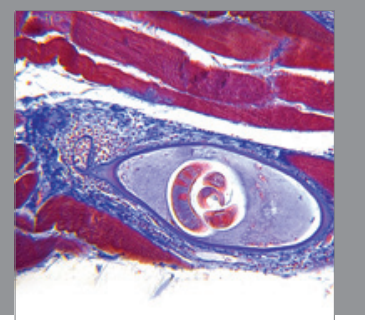

Gastroenterology

Research and Practice
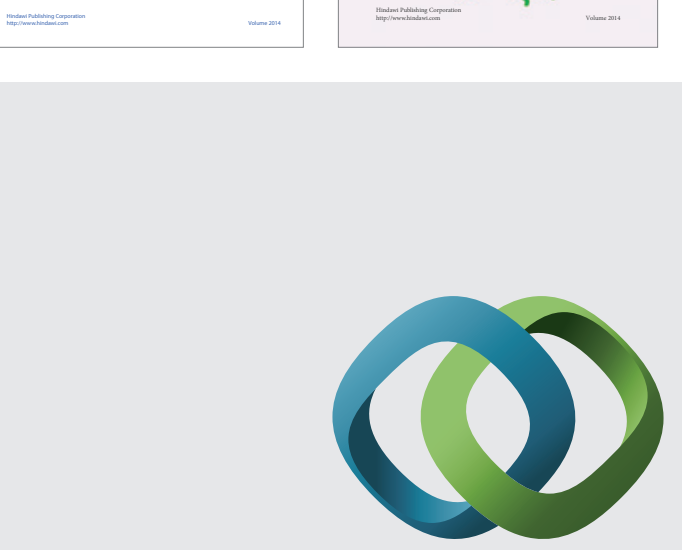

\section{Hindawi}

Submit your manuscripts at

http://www.hindawi.com
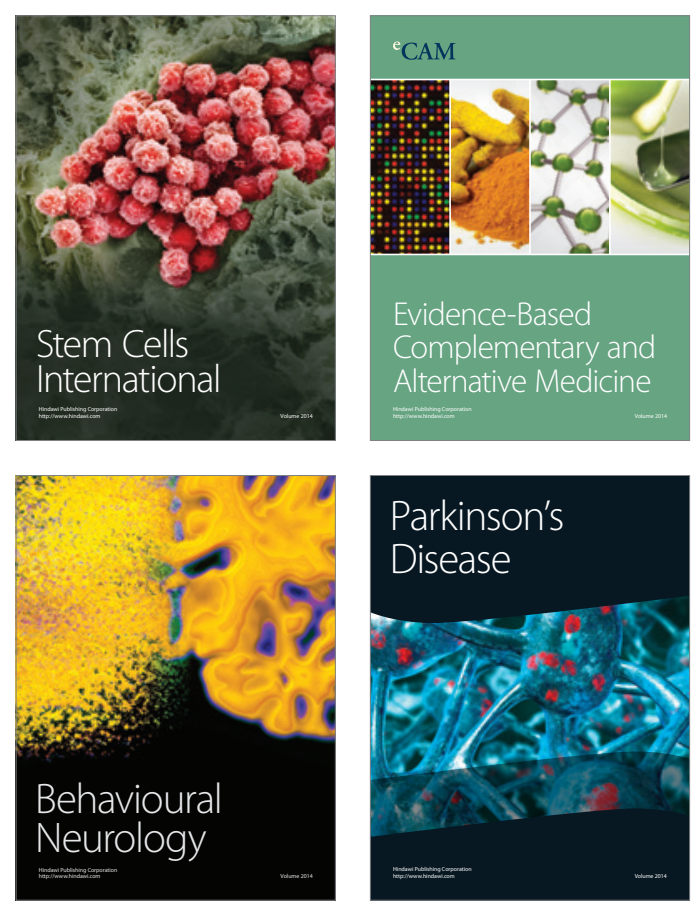

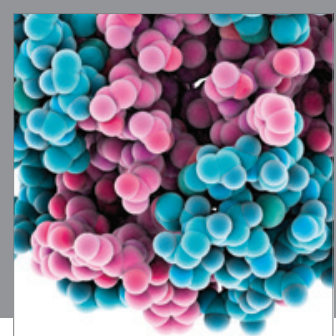

Journal of
Diabetes Research

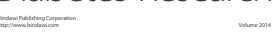

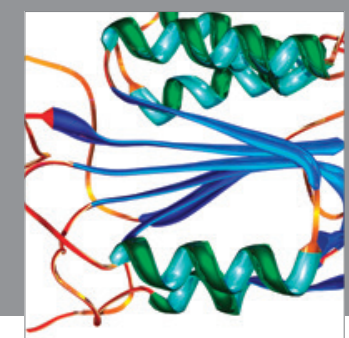

Disease Markers
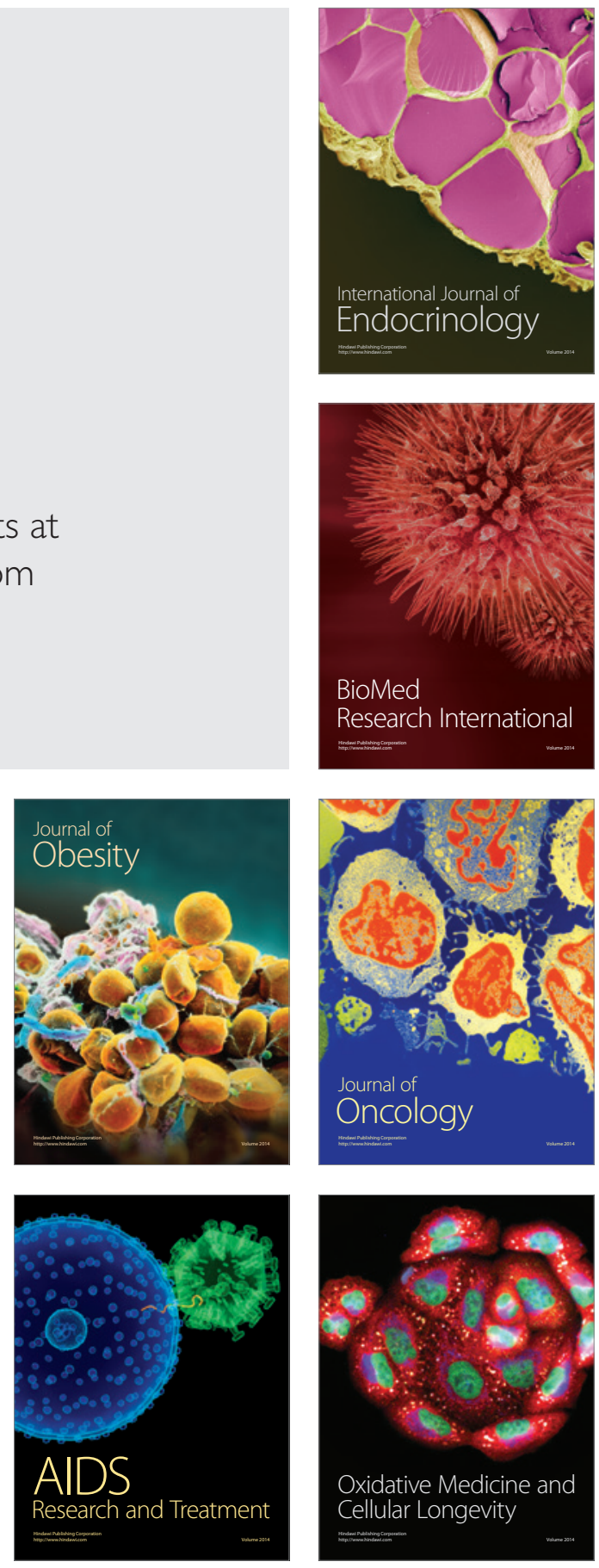